\title{
Medicinal Chemistry of the Anti-Diabetic Effects of Momordica Charan- tia: Active Constituents and Modes of Actions
}

\author{
Jaipaul Singh ${ }^{1}$, Emmanuel Cumming ${ }^{2}$, Gunasekar Manoharan ${ }^{1}$, Huba Kalasz $^{3}$ and \\ Ernest Adeghate*,
}

\begin{abstract}
${ }^{I}$ School of Pharmacy and Pharmaceutical Sciences and School of Forensic and Investigative Sciences, University of Central Lancashire, Preston, England, UK; ${ }^{2}$ School of Medicine, Faculty of Health Sciences, University of Guyana, Turkeyn, Georgetown, Guyana; ${ }^{3}$ Department of Pharmacology \& Therapeutics, Semmelweis University, Budapest, Hungary; ${ }^{4}$ Department of Anatomy, Faculty of Medicine and Health Science, United Arab Emirates, University, Al Ain, United Arab Emirates
\end{abstract}

\begin{abstract}
Diabetes mellitus (DM) is one of the oldest known human disease currently affecting more than 200 million people worldwide. Diabetes mellitus is derived from two Greek words meaning siphon and sugar. In DM, patients have high blood level of glucose and this passes out with urine. This is because the endocrine pancreas does not produce either or not enough insulin or the insulin which is produced is not exerting its biochemical effect (or insulin resistance) effectively. Insulin is a major metabolic hormone which has numerous functions in the body and one main role is to stimulate glucose uptake into body's cells where it is utilized to provide energy. The disease is classified into type 1 and type 2 DM. Type $1 \mathrm{DM}$ develops when the insulin producing $\beta$ cells have been destroyed and are unable to produce insulin. This is very common in children and is treated with insulin. Type 2 DM (T2DM) develops when the body is unable to produce an adequate amount of insulin or the insulin which is provided does not work efficiently. This is due to life style habits including unhealthy diet, obesity, lack of exercise and hereditary and environmental factors. Some symptoms of DM include excess urination, constant thirst, lethargy, weight loss, itching, decreased digestive enzyme secretion, slow wound healing and other related symptoms. If left untreated, DM can result in severe long-term complications such as kidney and heart failure, stroke, blindness, nerve damage, exocrine glands insufficiency and other forms of complications. T2DM can be treated and controlled by prescribed drugs, regular exercise, diet (including some plant-based food) and general change in life style habits. This review is concerned with the role of plant-based medicine to treat DM. One such plant is Momordica charantia which is grown in tropical countries worldwide and it has been used as a traditional herbal medicine for thousands of years although its origin in unknown. This review examines the medicinal chemistry and use(s) of M. charantia and its various extracts and compounds, their biochemical properties and how they act as anti-diabetic (hypoglycemic) drugs and the various mechanisms by which they exert their beneficial effects in controlling and treating DM.
\end{abstract}

keywords: Diabetes mellitus, Momordica charantia, hypoglycemic, insulin, pancreas.

\section{INTRODUCTION}

Diabetes mellitus (DM) is one of the oldest known human disease currently affecting about 200 million people worldwide [1]. It is estimated that by 2025 , more than 300 people globally will have confirmed DM and other 50 million undiagnosed $[2,3]$. This disease is the most common metabolic disorder in human and it is characterized by hyperglycemia, due to relative or absolute lack of insulin, the insensitivity of insulin or both $[4,5]$. DM is classified into type 1 or insulin-dependent DM (IDDM) or type 2 or noninsulin dependent DM (NIDDM) or T2DM [5,6]. Type 1 DM represents about $5-10 \%$ of all cases of DM whereas

*Address correspondence to this author at the Department of Anatomy, Faculty of Medicine and Health Sciences, P.O. Box 17666, Al Ain, United Arab Emirates; Tel: +971-3-7137496; Email: eadeghate@uaeu.ac.ae
T2DM accounts for $90-95 \%$ of diabetes. Type 1 DM is characterized mainly by auto-immune-mediated destruction of beta cells of the endocrine pancreas leading to reduced insulin secretion. This form of DM is prevalent in young children $[5,7]$. On the other hand, T2DM is characterized by insulin resistance and relative insulin deficiency and it is due to sedentary life style, genetic disposition, obesity, human behavior and environmental factors. Both forms of DM can lead to such long-term complications as neuropathy, retinopathy, cardiomyopathy, nephropathy, exocrine gland insufficiency and several other complications and eventually to death [5]. Type $1 \mathrm{DM}$ is treated mainly with insulin whereas T2DM is controlled by hypoglycemic drugs, regular exercise, general change in life style habits and diet including some plantbased food. The plant kingdom is a good potential source for the discovery of novel medicines to treat numerous diseases including DM. Currently, about 400 plants incorporated more than 700 recipes and compounds which have been 
evaluated extensively for the treatment of diabetes throughout the world [8-14]. In many parts of the world, especially in poor countries, this may be the only available form of therapy for the treatment of diabetic patients. One such plant is Momordica charantia (family name: Cucurbitaceae), nature's own cure for DM. M. charantia has been used extensively as an anti-viral, anti-bacterial agent and more so to treat a number of infections and diseases [13]. These include $\mathrm{DM}$, indigestion, fever, skin disease, HIV, viral and bacterial infections, hypertension, reduced cholesterol and inflammation, detoxification of the body, expelling worms from the body, balance certain hormones in the body, enhances immunity, promotes milk flow, prevents different tumors and several other reported medicinal benefits. This review is concerned specifically with the medicinal chemistry of $M$. charantia and its extracts and active constituents to treat DM.

\section{PLANT-BASED ANTI-DIABETIC MEDICINE}

Plant-based medicine has been used cost-effectively worldwide to treat DM. In fact, in many parts of the world, especially poor countries, this may be the only form of therapy available to treat diabetic patients. There are several reviews by different authors about anti-diabetic herbal plants [9-11, 13, 15-17]. One review has listed more than 300 plant species which possess hypoglycemic properties and classified them according to their biochemical names, country of origin, parts used and nature of the active agent(s) [11]. From the current literature, it is evident that $M$. charantia is the most widely used and popular anti-diabetic plant. Thus, this review will concentrate mainly on $M$. charantia and its anti diabetic properties [13].

\section{CHARACTERISTICS OF M. CHARANTIA}

Scientific name: Momordica charantia

Kingdom: Plantae

Division: Magnoliophyta

Family: Cucurbetaceae

Genus: Momordica

Species: Charantia

\section{Duration: Annual}

Some common names of M.charantia include bitter melon, papilla, bitter gourd, salsamino, corrila or karela, hanzal, assorossie, ampalaya, nigauri or goya, pare, kho gua, sora, balsam apple, pear or balsamina, and several other common names (see Taylor, 2002 [13] for extensive review and technical data). M. charantia is cultivated in many damp and wet tropical countries of the world including parts of South America and the Amazon basin including Brazil, Guyana and the Caribbean, East Africa and Asia including India, China, Philippines, Pakistan, Nepal and Sri Lanka. $M$. charantia is harvested both as food and as a medicine. It is a slender annual climbing vine with long leaves and at reproductive stage it produces warty or wrinkled gourd green fruits, resembling a squash or a cucumber. M. charantia is known for its very bitter taste and this is found in the leaves, the fruits, the stems and other parts of the plant [17]. The bitter taste is a distraction for eating the fruit but this is sometimes overshadowed by its beneficial effect. People normally boil the green leaves and stem and drink the bitter content as tea. Some people cook the fruit as a curry or with meat, while others eat it as a salad, fried it in oil or liquidize it into a herbal juice. In some cases people neutralize the bitter taste with the addition of a fruit (e.g. papaya) or a tropical juice such as mango or with a dash of salt. Commercially, the plant is used to make a powder which is sold commercially as tea or as in capsule form. Medicinally, the plant, its fruit and its powder extract possess a long history of use in the treatment of numerous diseases including diabetes $[9-11,13,15,17]$.

\section{EXTRACTS AND ACTIVE INGREDIENTS OF M. CHARANTIA}

Generally, the public have used different parts of $M$. charantia including the leaves, the stem and mainly the green fruits or seeds to treat diabetes. Table 1 shows the chemical structures of momocharin (1) and momordicin (2) which is believed to possess insulin-like chemical structure and properties. People eat the fruit raw, boil or cook the different parts or drink the pulp of the fruit as a juice. Over the years several scientists have tried to isolate the various active ingredient of $M$. charantia for commercial purpose.

Table 1. Chemical Structure of Momorcharin and Momorcidin

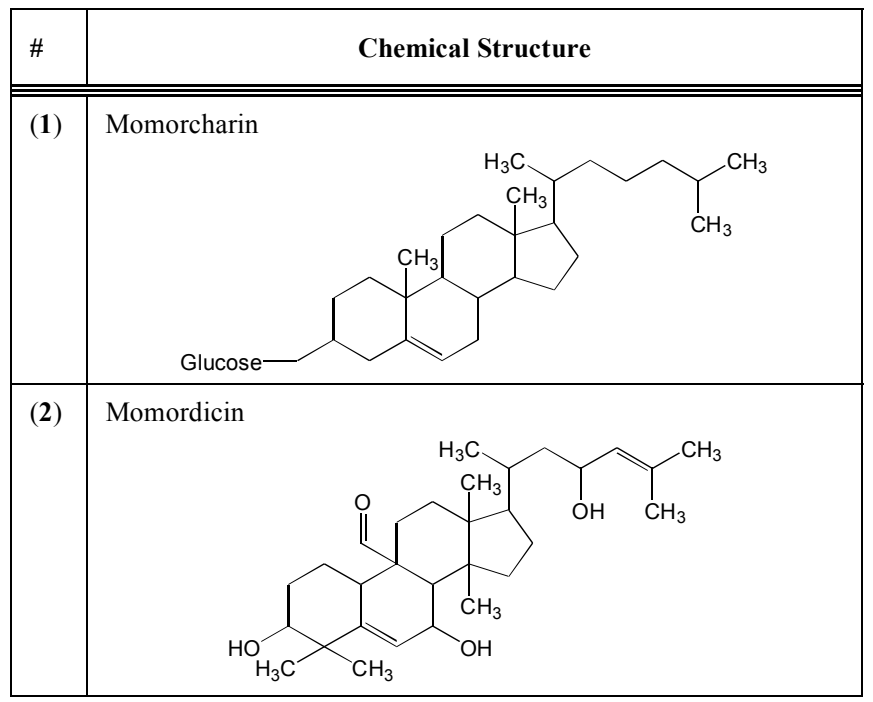

Fig. (1) shows a schematic diagram of the different stages of the isolation procedure for the active ingredient(s) of $M$. charantia fruit employing water and organic solvents. Initially, the fruits are chopped into small pieces and liquidized in deionized water. The green supernatant is separated from the cellulose and subsequently, the water is extracted using a rota-evaporator. The residue is dried in an oven and the green powder extract is used for experimentation or for further extraction, purification and identification employing HPLC, affinity chromatography, SDS-PAGE and NMR mass spectroscopic methods. Two medicinal compounds extracted from $M$. charantia include, charantin, a steroidal saponin agent with insulin-like properties and momordicin (2), an 


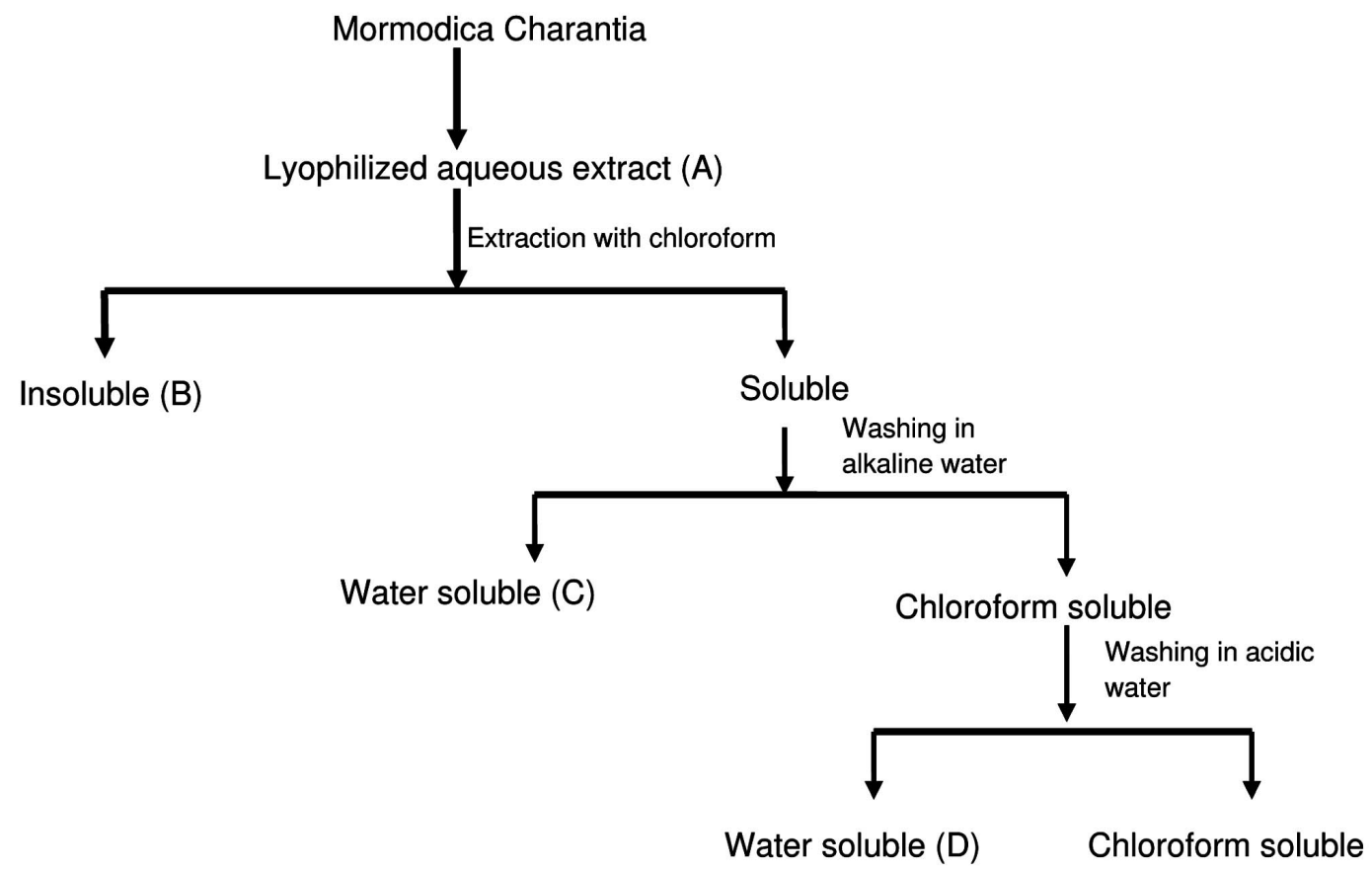

Fig. (1). Schematic diagram showing the isolation procedures for the active ingredient(s) of M. charantia fruit juice (redrawn from Day et al [19]). Further purification and identification procedures employ HPLC, affinity chromatography, SDS-page and mass spectrometry.

alkaloid responsible for the bitterness of the fruit [18]. In laboratory and clinical in vitro and in vivo studies scientists and clinicians have employed different water, ethanol and ether extracts as well as isolated biologically active phytochemicals including glycosides (momordin and charantin), alkaloids (momordicin (2)), polypeptide-P, oils from the seeds (linoleic, stearic and oleic acids), glycoproteins (alphamomorcharin (1), beta-momorcharin and lecitins) and others active compounds including protein MAP30 and vicine (pyrimidine nuclease) to study their hypoglycemic properties using both human and animal models [13]. Of these constituents, charantin, insulin-like peptides and alkaloids possess hypoglycemic properties. They are more effective when they are combined and they produce effects almost similar to the crude water soluble extract [13].

\section{COMPOUNDS PRESENT IN M. CHARANTIA}

Today around 228 different medicinal compounds have been isolated from the stems, leaves, pericap, entire plant, aerial parts of the plant, endosperm, callus tissues, cotyledons and mainly the seeds and unripe fruit in different laboratories in India, Japan, USA, Thailand, Egypt, China, Taiwan, Australia, Nigeria, Pakistan, Brazil, Nepal, Philippines and Peru [19].

These different compounds have been classified into different chemical types. These includes proteids, triterpenes, lipids, inorganic compounds, phenylpropanoids, carotenoids, steroids, alkaloids, monoterpenes, alkene to C3, carbohydrates, benzanoids, alkanol C5 or more, other unknown structure (e.g. kakara I-B, II-A and III-B) sterol and sesquiterpene. Of the 228 different compounds, most of these fall under the groups of proteids and triterpenes [13].

The plant has many different chemical components, which help medicinally either alone or when combined. One of the hypoglycemic components is a steroid saponin called momocharin (charantin) (1) with insulin-like chemical effect. Charantin has a molecular weight of $9.7 \mathrm{kDa}$ and it is the belief that charantin is the active hypoglycaemic agent of $M$. charantia.

Table 2 shows similarities in the chemical structures of momocharin (1), momordicin (2) and other commercially available hypoglycemic drugs (glibenclamide (3), gliclazide (4), Glipizide (5), Metformin hydrochloride (6), Pioglitazone hydrochloride (7) used in the treatment of T2DM. The hypoglycemic action of $M$. charantia and its isolated components may be due to its insulin-like structure. Recently, two other anti-diabetic constituents were isolated from $M$. charantia and both substances exerted hypoglycemic effects in mice. The cucurbitane triterpenoids were found to have the struc-

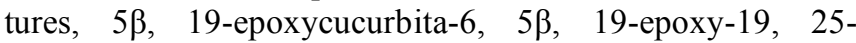
dimethoxycucurbita-6 23-(E)-dien-3 $\beta$-ol and $3 \beta-7 \beta-25-$ trihydroxy-cucurbita-5, 23 (E)-dien-19-al. These two compounds have more or less the same parent structure as $\alpha-\beta$ momocharin (1), and momordicin (2) [20]. More recently, momordicin 1 (2) was isolated from $M$. charantia and its chemical structure was characterized as momordicin 13,7 , 23,-Trihydroxycucurbitan-5,24-dien-19-al [20]. This compound is more or less similar to the one identifies by Harinantenaina et al. [21].

\section{TRADITIONAL REMEDY}

The literature has suggested that one-half of one cup of a standard leaves or whole herb concoction, 1-2 times daily is adequate for a hypoglycemic effect. Alternatively, an amount of one to two grams of the water extracted powder from either the leaf or fruit is adequate as a daily dose. Many people liquidize two to three green fruits with water or with a tropical juice and drink 10 to $20 \mathrm{ml}$ twice per day prior to meal. 
Table 2. Chemical Structures of Momorcharin (1), Momordicine (2), Glibenclamide (3), Gliclazide (4), Glipizide (5), Metformin Hydrochloride (6), Pioglitazone hydrochloride (7). Note similarities in structure momorcharin and Momordicin and Hypoglycemic agents

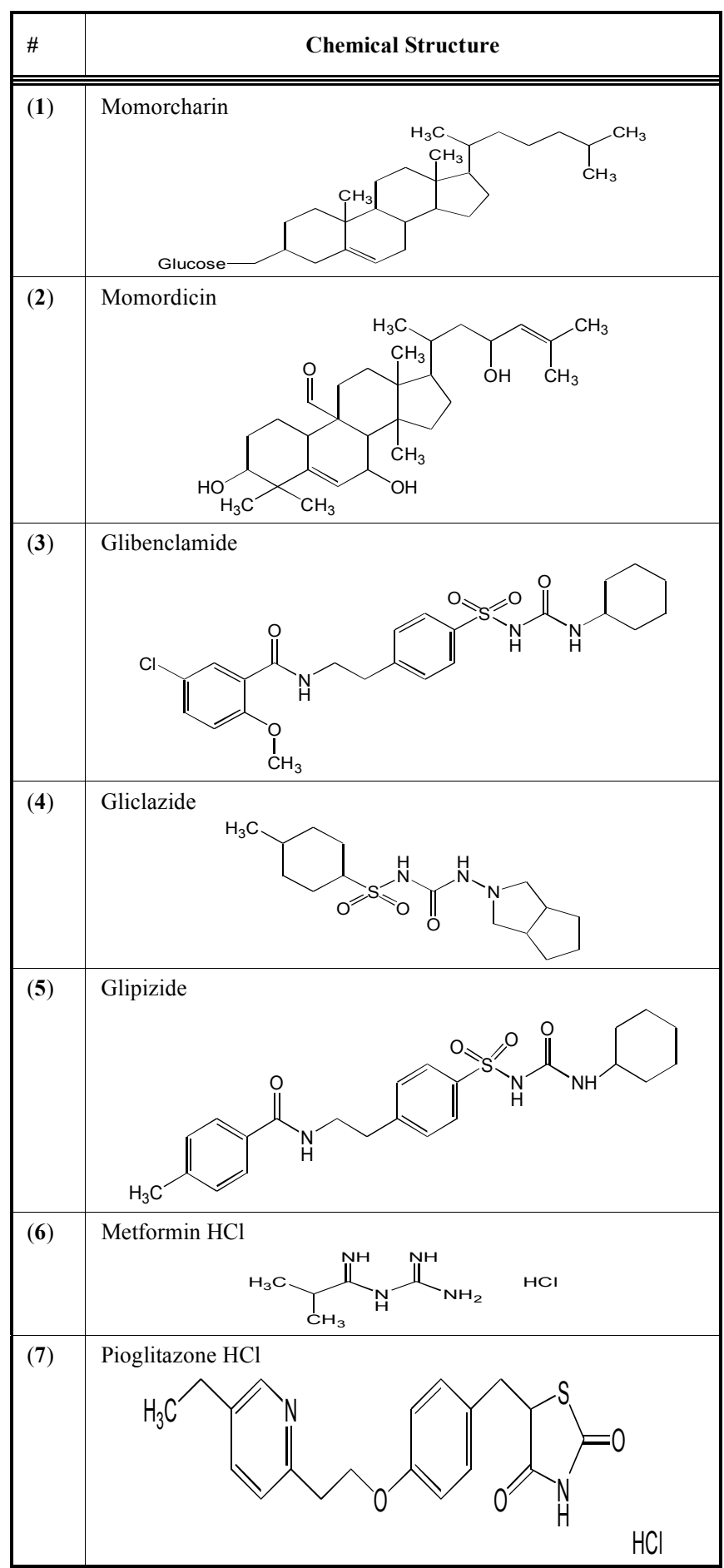

The question which people often ask is: can they take $M$. charantia with traditional commercial anti-diabetic drugs? The answer is to discuss the matter with their General Practitioner first. There may be an element of drug interaction be- tween $M$. charantia and commercially available anti-diabetic glucose lowering drugs but further experiments are required to determine the kind of interaction which may occur between a commercially available hypoglycemic drug and $M$. charantia or its hypoglycaemic extract [22]. For people with T2DM there is no harm in using $M$. charantia alone, but combine this regimen with regular physical exercise and modification of daily diet. Previous studies have described the pharmacology, clinical efficacy, adverse effects, drug interactions and place in therapy of $M$. charantia [22]. It is particularly noteworthy that $M$. charantia is an alternative herbal therapy that has been used primarily to reduce blood glucose level for thousands of years in patients with DM. Regarding adverse effects, some studies have reported hypoglycemic coma and convulsions in children, reduced fertility in mice, a fetish-like syndrome, increase in gamma glutamyltransferase and alkaline phosphatase levels in animals and some headaches [22].

\section{CLINICAL AND BASIC EXPERIMENTAL STUDIES}

Over the past 50 years, both basic and clinical studies have been done to determine the effect of $M$. charantia on the management of DM. Table 3 shows the effect of oral administration of $M$. charantia on both animal and human type 2 models. Today the literature contains over 40 studies employing adult human subjects and another 100 have employed animal models. They were administered with a hot water extract, concoction, the fruit, the fruit juice or the seeds [13]. Typically, of the twenty or more studies present in Table 3, only three have demonstrated no beneficial effects, one on T2DM patient [16], one in rabbit [23] and the other in rat [24]. However, the other seventeen studies have successfully demonstrated that the whole plant, ethanol extract, fruit juice, powder, concoction or seed can evoke hypoglycemic effects. The reason for the three unsuccessful findings may be due to the fact that the authors employed high doses of $M$. charantia. Previous studies have successfully demonstrated that $M$. charantia is more beneficial as a hypoglycemic agent only at therapeutic doses. Either pharmacological or high doses of $M$. charantia seem to exert inhibitory effects $[17,25]$. To date, not much study have been done on purified components of $M$. charantia in both human and animal models.

\section{POSSIBLE MODES OF ACTION OF M. CHARANTIA AND ITS EXTRACT}

M. charantia and its various extracts and components are believed to exert their hypoglycemic effects via different physiological, pharmacological and biochemical modes [13, $15,17,33]$. Table 4 lists some possible modes of the hypoglycemic actions of $M$. charantia and its various extracts and compounds. Today over 140 different studies worldwide [13] have investigated anti-hyperglycemic and hypoglycemic effects of the different extracts and ingredients of $M$. charantia in both human and animal models. These include the fruit extracts with, either hot water, ethanol, lyophilized, benzene, chloroform, acetone, fruit juice and powder. Of all the different studies, about 120 have reported active and beneficial effects, whereas the remaining 20 have reported inactive or no beneficial effects. There are several reasons for these dis- 
Table 3. Effects of Oral Administration of M. charantia on Diabetes Mellitus

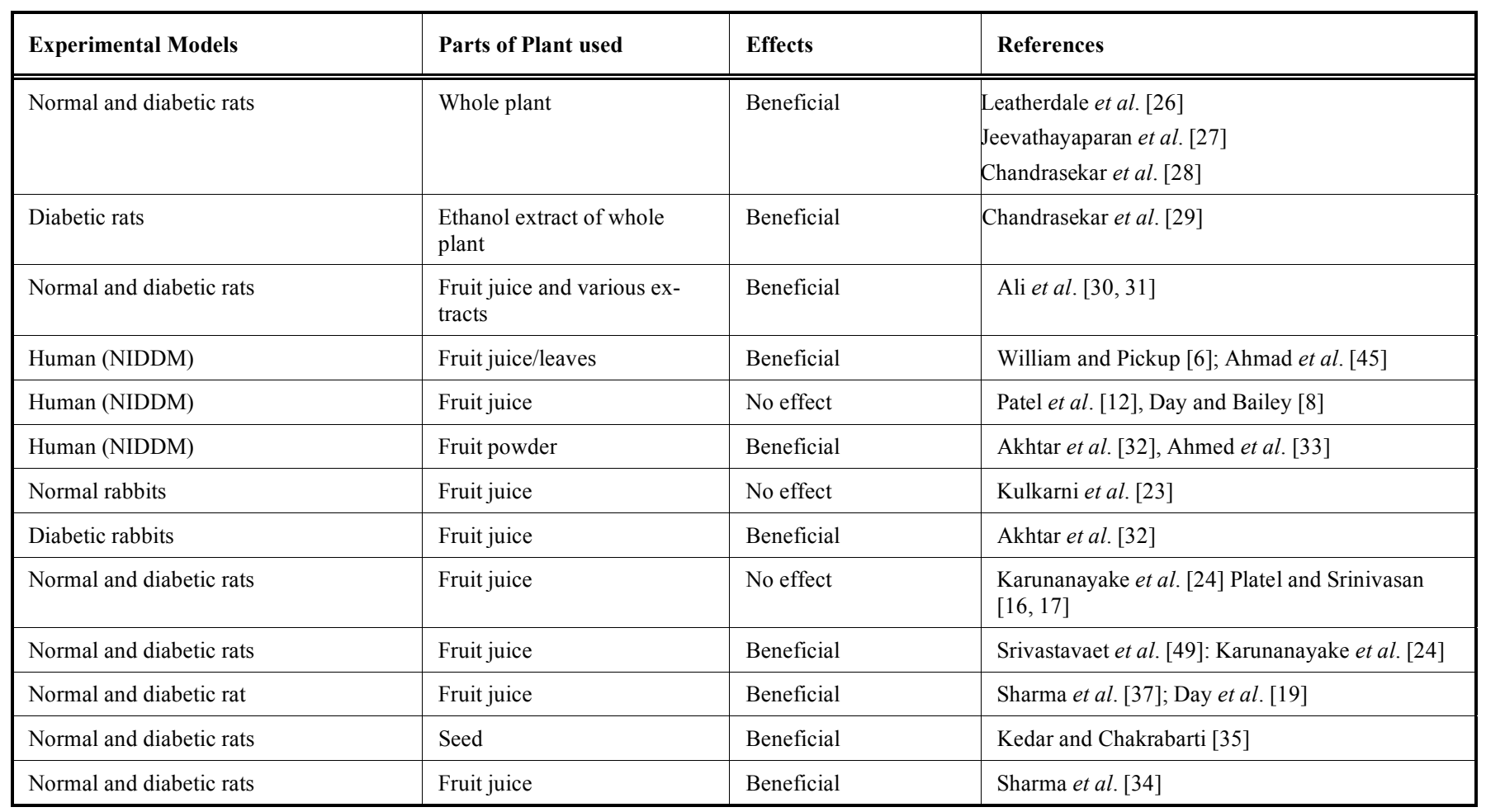

crepancies in the activity of $M$. charantia and its various extracts and isolated compounds. These may be due to the duration (short time period) of the experiments, doses of the compounds (high doses seem to evoke inhibitory or toxic effect) [32], the animal models and gender employed in the studies, the method of application/administration, and in some cases the laboratories and countries where the work was done and also the extracts administered. These discrepancies may also be due to seasonal variations [13].

M. charantia, its extracts and isolated components are believed to exert their hypoglycaemic effects via different physiological and biochemical processes. These include insulin secretagogue like effect, stimulation of skeletal muscle and peripheral cell glucose utilization, inhibition of intestinal glucose uptake, inhibition of hexokinase activity, suppression of key gluconeogenic enzymes, stimulation of key enzymes, HMP pathway and preservation of pancreatic islet cells and their functions (see Table 4 for relevant references).

\section{PRESERVATION OF PANCREATIC $\beta$ CELLS AND INSULIN SECRETION}

It was previously demonstrated by Jeewathayaparan et al. [25] that oral administration of M. charantia could lead to the secretion of insulin from endocrine pancreatic beta cells. This observation was further confirmed by Ahmed et al. [33, $39,41]$ who investigated the effect of daily oral administration of $M$. charantia fruit juice and the distribution of $\alpha, \beta$ and $\delta$ cells in the pancreas of streptozotocin (STZ)-induced diabetic rats using immunohistochemical methods. In these studies, they observed that $M$. charantia significantly increased the number of $\beta$ cells compared to untreated diabetic rats. However, the number of $\beta$ cells was significantly less than that obtained in normal and $M$. charantia-treated control rats. This may be due to the fact that the study was only done for a period of 10 weeks and moreover, the STZ probably destroyed some of the beta cell completely one week prior to the administration of the fruit juice to the animals. From these studies, the authors concluded that $M$. charantia fruit juice may have a role in the renewal of $\beta$ cells in treated diabetic rats or alternatively, the juice may permit the recovery of partially destroyed $\beta$ cells $[33,39,41]$. Physiological experiments have also shown that $M$. charantia can stimulate insulin secretion from the endocrine pancreas [42] and elicit glucose uptake in the liver [43]. Current evidence therefore indicates that the recovery and subsequent increase in the number of insulin producing cells followed by the release of insulin may be part of the several pathways by which $M$. charantia exerts its hypoglycemic effects. In addition to the properties mentioned above, M. charantia and its extracts may possess cell-like proliferation and growth-like properties similar to that of insulin $[5,25]$. Nevertheless, further experiment are required, at least at the molecular level, to determine the precise mechanisms whereby $M$. charantia can either repair damaged $\beta$ cells or prevent their death.

\section{CHARANTIA AND GLUCOSE METABOLISM}

Insulin plays a major biochemical role in stimulating the uptake of glucose by different cells of the body for the production of energy $[4,5,25]$. Since $M$. charantia and its various extracts and components have been reported to exert hypoglycemic effects, then it is important to understand whether $M$. charantia may have a direct effect in inducing a reduction in blood glucose level [13]. Previous studies have shown that both the aqueous and alcoholic extracts of the fruit of $M$. charantia can inhibit the activities of fructose 1 , 
Table 4. Possible modes of hypoglycaemic actions of M. charantia

\begin{tabular}{|l|l|l|}
\hline \multicolumn{2}{|l|}{ Possible Modes of Action } & Reference \\
\hline 1. & Insulin secretagogue effect & Karunanayake et al. [24], Kedar and Chakrabarti [35], Jeevathayaparan et al. [27] \\
\hline 2. & $\begin{array}{l}\text { Stimulation of peripheral and skeletal muscle glucose } \\
\text { utilisation }\end{array}$ & Day et al. [19]); Bailey and Day [8], Cummings et al. [25] \\
\hline 3. & Inhibition of intestinal glucose uptake & Meir and Yaniv [47]; Ahmed et al. [33], Ahmed et al. [40] \\
\hline 4. & Inhibition of hexokinase activity & Meir and Yaniv [47] \\
\hline 5. & Suppression of key gluconeogenic enzymes & Shibib et al. [48] \\
\hline 6. & Stimulation of key enzyme of HMP pathway & Shibib et al. [48] \\
\hline 7. & Preservation of islet beta cells and their functions & Ahmed et al. [39]; Ahmed et al. [40] \\
\hline
\end{tabular}

6-diphosphatase and glucose-6-phosphatase and at the same time stimulating the action of glucose-6-phosphatase dehydrogenase $[17,19,34,36]$. It was previously reported that $M$. charantia and its various extracts can stimulate peripheral cell glucose uptake $[17,19,25]$. A number of studies have investigated the effect of the powder and chloroform extract of $M$. charantia in comparison with insulin on glucose and amino acid uptakes by skeletal $\mathrm{L} 6$ myotubes and $\mathrm{Na}^{+}$and $\mathrm{K}^{+}$ glucose uptakes by jejunum brush border membrane vesicles in both age-matched control and STZ-induced diabetic rats. The results show that either the lyophilized fruit juice or chloroform extract at $5-10 \mu \mathrm{gl}^{-1}$ can stimulate ${ }^{3} \mathrm{H}-$ deoxyglucose and ${ }^{14} \mathrm{C}-\mathrm{Me}$ AIB (N-methyl-amino- $\alpha$ isobutyric acid) uptakes by L6 myotubes. These effects were similar in magnitude to the effects obtained with $100 \mathrm{nM}$ insulin. Incubation of either insulin or $M$. charantia juice in the presence of wortmannin (a phosphatidylinositol 3-kinase inhibitor) resulted in a marked inhibition of ${ }^{3} \mathrm{H}$-deoxyglucose uptake by L- 6 myotubes $[25,44]$. Together, the results have clearly demonstrated that $M$. charantia contains insulin like properties, similar to one phytochemical component of $M$. charantia called V-insulin [13].

In addition to its insulin-like effects on skeletal muscle cells, daily oral intake of $M$. charantia fruit juice over a period of 10 weeks significantly reduced the amount of $\mathrm{Na}^{+}$ and $\mathrm{K}^{+}$-dependent ${ }^{14} \mathrm{C}$-D-glucose absorbed by rat jejunum brush border membrane vesicle compared to vesicles obtained from STZ-induced diabetic rats [33,41]. Taken together, these results clearly demonstrated that $M$. charantia and its extracts can directly regulate blood glucose via two mechanisms. Firstly, it can regulate how much glucose is absorbed by the gut into the blood following a meal and secondly, it can stimulate glucose uptake into skeletal muscle cells just like insulin. Moreover, it seems to exert its effect via the same intracellular signaling pathways as insulin in regulating glucose metabolism in the body [44].

\section{ANTI NEUROPATHIC EFFECT OF M. CHARANTIA FRUIT JUICE}

Human diabetic neuropathy is both cumbersome and complicated and it may result in severe disability $[5,6]$. In addition, treatment of diabetic neuropathy is very expensive. The most cost effective way is to either prevent or delay the onset of this, long-term diabetic complication. The influence of $M$. charantia fruit extract and insulin on the ultrastructural abnormalities of myelinated fibers in experimental diabetes in rats was investigated in previous studies $[33,37$, 40].

The results have shown that the mean cross-sectional myelinated fibre area, axonal area and myelin area including the mean maximum myelinated fibres area were significantly less in untreated diabetic rats when compared with agematched controls. In the $M$. charantia treated diabetic animals, myelinated fibre area and myelin area were significantly greater than untreated diabetics and not significantly different from age-matched controls. The mean value for the maximum fibre area was also significantly greater than untreated diabetics and was not significantly different from age-matched controls. The axon to fibre ratio ('g' ratio) did not differ between any of the experimental groups. It was concluded that the administration of $M$. charantia fruit juice not only reduced blood glucose level but also corrected the structural abnormalities of peripheral nerves in experimental diabetes. These results have strongly indicated that $M$. charantia possesses growth factor-like properties just like insulin $[5,31,37,39]$.

To date, $M$. charantia has been extensively studies worldwide for its medicinal properties to treat a number of diseases [38]. It is described as a versatile plant worthy of treating almost any disease inflicted on mankind. This may be due to the fact the plant possesses over 225 different medicinal constituents [13]. These different compounds may act either separately or together to exert their medicinal effects. In relation to diabetes [46], only charantin, insulin-like peptide and alkaloid-like extracts possess hypoglycemic properties similar to the plant itself or its crude extracts. These different compounds seem to exert their beneficial effects via several mechanisms to control and treat diabetes mellitus.

\section{REFERENCES}

[1] Amos, A.; McCarthy, D.; Zimmet, P. The rising global burden of diabetes and its complications; estimates and projections to the year 2010. Diabet. Med., 1997, 14, S1-S85.

[2] Zimmet, P. Globalization, coca-colonization and the chronic disease epidemic: can the Doomsday scenario be averted? J. Intern. Med., 2000, 247, 301-310.

[3] Zimmet, P.; Shaw, J.; Alberti, K.G. Preventing Type 2 diabetes and the dysmetabolic syndrome in the real world: a realistic view. Diabet. Med., 2003, 20, 693-70. 
[4] Sattiel, A.L.; Khan, C.R. In insulin signalling and regulation of glucose and lipid metabolism. Nature, 2001, 414, 799 -806.

[5] Kumar, P. J.; Clark, M. Diabetes mellitus and other disorders of metabolism. In: Textbook of Clinical Medicine. Saunders (London), 2005, 1069-1121.

[6] Williams, G.; Pickup, J.C. New drugs in the management of diabetes mellitus. In: Pickup, J.C. Textbook of Diabetes II Blackwell, Oxford, 1991, 977-993.

[7] Harrison, L.; Kay, T.; Colman, P.; Honeyman, M. Diabetes in the new mellineum. The Endocrinology and Diabetes Research Foundation of the University of Sydney, 1999, 85-100.

[8] Bailey, C.J.; Day, C. Traditional plant medicine as treatment for diabetes. Diabetes Care, 1989, 12, 553-564.

[91 Ivorra, M.D.; Paya, M.; Villar, A. A review of natural products and plants as potential anti-diabetic drugs. J. Ethnopharmacol., 1989, 27, 243-275.

[10] Tanira, M.O. M. Anti-diabetic medicinal plants; a review of the present status and future directions. Int. J. Diabetes, 1994, 2, 15-22.

[11] Attar-ur-Rahman, A.; Zaman, K. Medicinal plant with hypoglycaemic effects. J. Ethnopharmacol., 1989, 26, 1-55.

[12] Patel, J.C.; Dhirawani, M.K.; Doshi, J.C. Karela: In the treatment of diabetes mellitus. Indian J. Med. Sci., 1968, 22, 30-32.

[13] Taylor, L. Bitter Melon (Momordica charantia). Herbal Secrets of the Rainforest. 2nd edition. Sage Press. Austin Texas, USA, 2002, 1-100.

[14] Ogunleye, D.S.; Adeyemi, A.A.; Sanni, A.M. Hypoglycaemic activities of the stem bark of Cola acuminata Vahl and leaf of Ficus exasperata (P, Beauv) Schott and Endl. Nig. Quart Hosp. Med., 2003, 13 (1), 58-60.

[15] Garau, C.; Cummings, E.; Phoenix, D. A.; Singh, J. Beneficial effects and mechanism of action of Momordica charantia in the treatment of diabetes mellitus: a mini review. Int. J. Diabetes Metab., 2003, 11, 46-55.

[16] Platel, K.; Srinivasan, K. Plant food in the management of diabetes mellitus: Vegetables as potential hypoglycaemic agents. Nahrung, 1999, 41, 68-74.

[17] Platel, K.; Srinivasan, K. Effect of dietary intake of freeze-dried bitter gourd (Momordica charantia) in streptozotocin induced diabetic rats. Nahrung, 1997, 39, 262-268.

[18] Pitipanponga, J.; Chitprserth, S.; Gotoc, M.; Jiratcharlyakuid, W.; Sasakic, M.; Shetipruk, A. New approach for extractionof charantin from Momordica charantia next term with pressurized liquid extraction. Separatio Purification Technol., 2007, 52 (3), 416-422.

[19] Day, C.; Cartwright, T.; Provost, J.; Bailey, C. J. Hypoglycaemic effects of Momordica charantia extract. Planta Med., 1990, 56, 426-429.

[20] Puspawati, N. M. Isolation and identification momordicin i from leaves extract of Momordica charantia L. J. Kimia, 2008, 2 (1), 5356.

[21] Harinantenaina, L.; Tanaka, M.; Takaoka, S.; Oda, M.; Mogami, O.; Uchida, M.; Asakawa, Y. Momordica charantia constituents and antidiabetic screening of the isolated major compounds. Chem. Pharm. Bull., 2006, 54, 1017-1021.

[22] Basch, E.; Gabardi, S.; Ulbright, C. Bitter melon (Momordica charantia); A review of efficacy and safety. Am. J. Health Syst. Pharm., 2003, 60, 356-359.

[23] Kulkarni, R.D.; Gaitonde, B.B. Potentiation of tolbutamide action by jasad bhasma and karela (Momordica charantia). Indian J. Med. Res., 1962, 50, 715-719.

[24] Karunanayake, E.H.; Welihinda, J.; Sirimanne, S.R.; Sinnadorai, G. Oral hypoglycaemic activity of some medicinal plants of Sri Lanka. J. Ethnopharmacol., 1984, 11, 223-231.

[25] Cummings, E.; Hundal, H.S.; Wackerhage, H.; Hope, M.; Belle, M.; Adeghate, E.; Singh, J. Momordica charantia fruit juice stimulates glucose and amino acid uptakes in L6 myotubes. Mol. Cell Biochem., 2004, 261, 99-104.

[26] Leatherdale, B.A.; Panesar, R.K.; Atkins, T.W.; Bailey, C.J.; Bignal, A.H.C. Improvement in glucose tolerance due to momordica charantia (karela). Brit. Med. J., 1981, 282, 1823-1824.

[27] Jeevathayaparan, S.; Tennekoon, K.H.; Karunanayake, E.H. A comparative study of the oral hypoglycaemic effect of Momordica charantia fruit juice and tolbutamine in streptozotocin induced graded severity diabetes in rat. Int. J. Diabetes., 1995, 3, 99-108.
[28] Chandrasekar, B.; Bajpai, M.B.; Mukherjee, S.K. Hypoglycemic activity of Swertia chirayita (Roxb.ex Flem.) Karst. Ind. J. Exp. Biol., 1990, 28, 616-618.

[29] Chandrasekar, B.; Mukherjee, B.; Mukherjee, S.K. Blood sugar lowering potentiality of selected Cucurbitaceae plants of Indian origin. Ind. J. Med. Res., 1989, 90, 300-305.

[30] Ali, L.; Khan, A.K.A.; Mamun, M.I.R.; Mosihuzzaman, M.; Nahar, N.; Nur-e-Alam, M.; Rokeya, B. Studies on the hypoglycaemic effects of fruit pulp, seed and whole plant of Momordica charantia on normal and diabetic model rats. Planta Med., 1993, 59, 408-412.

[31] Ali, L.; Khan, A.K.; Hassan, Z.; Mamun, M.I.R.; Mosihuzzaman, M.; Nahar, N.; Nur-e-Alam, M.; Rokeya, B. Insulin releasing properties of fractions from Momordica charantia fruit on isolated rat islets. Diabetologia, 1993, 36 (1), 181-193.

[32] Akhtar, M.S.; Arhar, M.A.; Yaqub, M. Effect of Momordica charantia on blood glucose level of normal and alloxan diabetic rabbits. Planta Med., 1991, 42(3), 202-212.

[33] Ahmed, I.; Sharma, A.K.; Ponery, A.S.; Bener, A.; Singh, J. The influence of Momordica charantia on ultrastructural abnormalities of myelinated fibres in experimental diabetes. Int. J. Diabetes, 1999, 7, 110-121.

[34] Sharma, A. K.; Ahmed, I.; Tadayyon, M.; Ponery, A.S.; Aloamaka, P.; Asood, G.; Pallot, D.J. The beneficial effects of Momordica charantia fruit juice on streptozotocin -induced diabetes and hypertension in rats. Int. J. Diabetes, 1996, 4, 29-38.

[35] Kedar, P.; Chakrabarti, C.H. Effects of bittergourd (Momordica charantia) seed and glibenclamide in streptozotocin induced diabetes mellitus. Indian J. Exp. Biol., 1982, 20, 232-235.

[36] Day, C. Hypoglycaemic compounds from plants. In: New Antidiabetic Drugs (Eds. Bailey, C. J.; Flat, P. R., Nishimura Ltd, Japan, 1990, 267-278.

[37] Sharma, A.K.; Duguid, I.G.M.; Blanchard, D.S.; Thomas, P.K. The effect of insulin treatment on myelinated nerve fibre maturation and integrity and on body growth in streptozotocin-diabetic rats. $J$. Neurol. Sci., 1985, 67, 285-297.

[38] Sharma, V.N.; Sogani, R.L.; Arora, R.B. Role of Momordica charantia in the treatment of diseases. Indian J. Med. Res., 1950, 48, 471-477.

[39] Ahmed, I.; Adeghate, E.; Sharma, A.K.; Pallot, D.J.; Singh, J. Effects of Momordica charantia fruit juice on islet morphology in the pancreas of the streptozotocin-diabetic rat. Diabetes Res. Clin. Pract., 1998, 40, 145-151.

[40] Ahmed, I. Effects of Momordica charantia fruit juice on experimental diabetes and its complications. PhD Thesis. University of Central Lancashire, Preston, UK, 1999.

[411 Ahmed, I.; Cummings, E.; Sharma, A.K.; Adeghate, E.; Singh, J. Beneficial effects and mechanism of action of Momordica charantia fruit juice in the treatment of streptozotocin-induced diabetes mellitus in rats. Mol. Cell Biochem., 2004, 261, 63-70.

[42] Welihinda, J.; Arvidson, G.; Gylfe, E.; Hellman, B.; Karlsson, E. The insulin-releasing activity of the tropical plant Momordica charantia. Acta Biologica et Medica Germanica, 1982, 41, 12291240 .

[43] Welihinda, J.; Karunanayake, E.H.; Sheriff, M.H.R.; Jayasinghe, K.S.A. Effect of Momordica charantia on glucose tolerance in maturity onset diabetes. J. Ethnopharm., 1986, 17, 277-282.

[44] Lee, A.D.; Hansen, A.; Hollosby, A. Wortmannin inhibits insulin stimulated but not contraction stimulated glucose activity in skeletal muscle. FEBS Letts., 1985, 361, 51-54.

[45] Ahmad, N.; Hassan, M.R.; Halder, H.; Bennoor, K.S. Effect of Momordica charantia (Karolla) extracts on fasting and postprandial serum glucose levels in NIDDM patients. Bangladesh Med. Res. Coun. Bull., 1999, 25, 11-13.

[46] Harris, M.; Zimmet, P. Classification of Diabetes Mellitus and other categories of glucose intolerance. In: International Textbook of Diabetes Mellitus, $2^{\text {nd }}$ Edition (Eds. Alberti, K.; Zimmet, P.; De Fronzo, R., Wiley, Chichester), 1997, 9-23.

[47] Meir, P.; Yaniv, Z. An in vitro study on the effect of Momordica charantia on glucose uptake and glucose metabolism in rats. Planta Med., 1995, 1, 12-16.

[48] Shibib, B. A.; Khan, L.A., Rahman, R. Hypoglycaemic activity enzymes glucose-6-phosphatase and fructose-1,6-bisphosphatase and elevation of both liver and red-cell shunt enzyme glucose-6phosphate dehydrogenase. Biochem. J., 1993, 292, 267-270. 
[49] Srivastava, Y.; Venkatakrishna-Bhatt, H.; Verma, Y.; Venkaiah, K.; Raval, B.H. Antidiabetic and adaptogenic properties of Mo- mordica charantia extract: An experimental and clinical evaluation. Phytother. Res., 1993, 7, 285-289.

Received: January 02, 2011

Revised: February 18, 2011

Accepted: March 03, 2011

(C) Singh et al.; Licensee Bentham Open.

This is an open access article licensed under the terms of the Creative Commons Attribution Non-Commercial License (http: //creativecommons.org/licenses/by$\mathrm{nc} / 3.0 /$ ) which permits unrestricted, non-commercial use, distribution and reproduction in any medium, provided the work is properly cited. 